\title{
The role of cognitive functions in the dynamics of work accidents
}

\author{
Daniel George Tanasievici ${ }^{1}$, Gabriela Caldarescu $^{1 *}$, Constantin Baciu $^{2}$, and Elena \\ Matcovschi $^{2}$ \\ ${ }^{1}$ Labor Inspectorate Iasi, Fire Mill Road no. 31, 707410 Iasi, Romania \\ 2“'Gheorghe Asachi”' Technical University of Iasi, Faculty of Materials Science and Engineering, D. \\ Mangeron Blv., no. 41, 700050 Iasi, Romania
}

\begin{abstract}
This paper brings to the fore the need to study the causality of work accidents starting from the hypothesis that the causes must be identified immediately, respectively the dysfunctions of the work system, which contribute to their occurrence. So, in the causal chain of the work accident, the last link is the "meeting" between the victim and the material agent who injures her, and often the factors of the work system, which are potential causes of injury, are specific to the worker and represent an error inappropriate behaviour in terms of occupational safety, in the form of wrongdoing or omissions. In this regard, cognitive ergonomics is still an untapped area, although it can make significant contributions to improving work performance and creating safe and healthy working environments in industry. Cognitive functions are relevant when we talk about 4 essential skills of the worker, respectively: sensation and perception, attention, short and long term memory. The paper brings more information for the scientific community because the analysis highlights the link between the cognitive functions of workers and the errors generated by them in the dynamics of a work accident, and can also be a starting point for new research.
\end{abstract}

\section{Introduction}

Work accidents have social and economic consequences which, quantifiable or not, often produce irreversible changes. The legal consequences, often ignored by the employer but also by the employee, can be major if a serious and imminent danger of an accident at work and / or an occupational disease is created and can constitute a crime. The dysfunctions of the work system generated by disorders, qualities, intrinsic properties of the 4 constituent elements (executor, workload, means of work, work environment) can produce events, but do not always lead to injury or change in the health of the performer (the worker), but only in the situation where a causal chain is constituted, whose last link is the interaction between the victim and the factors that injure him (risks of injury and occupational disease). The notion of "work accident" is always used with reference to the executor (the human factor) who has

\footnotetext{
* Corresponding author:gtcaldarescu@,gmail.com
} 
suffered a deterioration of his work capacity or died during the professional activity and due to it.

Studying the causality of accidents provides a way to analyse accidents from the individual to the organizational level. A chronology of events is a primary step for the task and further determination of the critical ones is of vital importance. For each critical event, unsafe actions and unsafe conditions must first be identified, which are considered to be the immediate causes. On this basis, unsafe behaviours (meaning safety and health knowledge of people, awareness, habits, psychological and physiological state), deficiencies in the organizational system of occupational safety and health management, and elements of culture can be further deduced one by one. Causal research can be an attribute of engineers specializing in occupational safety and health, but also of sociologists, psychologists and doctors, all categories of specialists being concerned with conducting research. From all these studies two different theories emerge: work accidents occur either due to the inability of workers to cope with hazards at work, or due to external causes such as work schedule, hazardous technical equipment, workload or work pace.

\section{Relevant theories regarding the causality of work events I accidents. Benefits and limits}

The causality of the occurrence of work events / accidents has been studied by researchers in the field, and the most relevant theories are: the Greenwood and Woods model of accidents; the causal model of Heinrich's domino accident; Rasmussen Risk Management Framework (AcciMap); Wiegmann and Shappell's Human Factor Analysis and Classification System (HFACS); theoretical modelling of accidents of Leveson systems and Process Model (STAMP). Each theory generates its own distinct approach when used for accident analysis, but by comparison their common disadvantage is that they fail to define the cause of the accident at each level so that people prevent accidents by directly, accurately or conveniently applying analytical processes and interpreting their results.

\subsection{The Greenwood and Woods model of accidents}

The theory of "accident predisposition" was the first scientific theory that tried to explain accidents and is perhaps the best-known theory of causing accidents at work.

This theory states that accidents at work occur where there are workers who, due to psychological and behavioural characteristics, are more likely than others to be involved in accidents. Greenwood and Woods concluded from their studies that this type of worker could be identified and excluded from dangerous jobs, this reducing the rate of accidents at work significantly [1,2]. Greenwood and his colleagues used a static, mechanical system, ignoring factors such as heat, noise, lighting, toxic substances, inexperience, fatigue, speed of work, factors that can contribute to these events. Greenwood has failed to explain how the psychological or behavioural characteristics of workers who predict these accidents can be identified $[3,4]$.

\subsection{The causal model of Heinrich's domino accident}

The occupational accident causation model based on the "five dominoes" principle is a sequential accident model that has influenced thinking in the field of occupational safety and health. Heinrich's (1950) theory presents work accidents as a causal chain of events, represented as a domino that overturns in a chain reaction, on the principle of the fall of the 
first domino that leads to the fall of the second, third, etc. The theory states that injuries can be predicted if the causal chain based on the domino principle is interrupted by the elimination of a domino piece, a risk factor, the accident model being linear and simple to understand. The theory is based on 5 factors (domino type pieces): character traits of workers; the personal negligence or failure of the worker, which causes him to pay insufficient attention to the task; an unsafe action or a mechanical / physical danger, such as an error of the worker (sitting under suspended loads, starting the machine without warning ...) or a malfunction of the technical equipment or insufficiently protected machine; accidentally; injuries or losses, the consequences of the accident. This linear accident pattern is simple and easy to understand. Compared to the very simplistic analyzes that were common at the time ("accident caused by a worker's error"), it helped managers to think and identify the underlying causal factors that could contribute to accidents. Its promise to allow the accident sequence to be interrupted by acting on the underlying causal factors ("removing a domino") helps to persuade people to take the corrective actions suggested by the accident investigation. This model is considered today to be too simplistic to be a useful tool to help understand the causal factors of accidents, it presents an overly simple view that is inappropriate in complex systems where accidents are generally caused by many interacting factors $[5,6]$.

\subsection{Rasmussen Risk Management Framework (AcciMap)}

Due to the development of technology and not only the investigation of work accidents has evolved, and at this time may be private as coming from an unfavourable organizational context.

Risk management according to the AcciMap approach is useful for discovering how factors in different parts of the work system contributed to an accident and for positioning them in a logical causal diagram that illustrates how an event occurred. The method also promotes a systemic view of the cause of accidents, as the AcciMap diagram extends beyond the immediate causes of the event and reveals a number of higher-level factors that contributed to the occurrence of the event. Therefore, this approach helps specialists to understand how and why an accident occurred at work, eliminating the risk of them focusing only on the immediate causes (mistakes made by workers). This approach does not allow guilt to be established only for front-line workers.

Structurally, the AcciMap approach involves building a multi-layered causal diagram in which the different causes of an accident are arranged according to their causal departure from the end result. The precise format of the diagram varies depending on the purpose of the analysis, but lower levels are usually immediate precursors of the event, which refers to the activities of workers and the physical events, processes and conditions that contributed to the result [7].

\subsection{Wiegmann and Shappell's Human Factor Analysis and Classification System (HFACS)}

The Human Factor Analysis and Classification System (HFACS), originally adapted from the model of Reason (1990) by Wiegmann and Shappell (2003), identifies four levels within an organization where latent and active human errors can occur: organizational influences, unsafe supervision, preconditions for uncertain facts and uncertain facts.

The theoretical model of causality of accidents proposed by Reason's (1990) - the model of human reason aims to explain how accidents occur in organizations and between its levels. The main assumption of the theory is that accidents occur in such a way that the causes are related to the levels of the organization. A second assumption of the model is that the 
components of organizations are required to work together at least to prevent accidents. From these hypotheses, Reason's theorizes that in most accidents active and latent human errors result from previous latent human errors at levels higher than the organizational levels that are to blame for the occurrence of the event. These combinations of latent errors pose the greatest threat to complex system security. According to Wiegmann and Shappell (2003), the percentage of accidents involving human error varies from $70 \%$ to $80 \%$. In addition, in terms of causality, the percentage of work accidents attributed to human error has increased compared to those attributed to equipment failures in the last 40 years (Shappell \& Wiegmann, 2000).

Based on the Human Error Reason Model, HFACS (Shappell and Wiegmann, 2000) has been used to analyse especially aviation accidents [8].

\subsection{Theoretical modelling of Leveson systems accidents and process model (STAMP)}

The theoretical model called STAMP (Systems-Theoretic Accident Model and Processes) claims that systems theory is a useful way to analyze accidents, especially system accidents. In this view, accidents occur when there are external disturbances, component failures or dysfunctional interactions between system components and are not properly managed through a control system, resulting from inadequate control or application of safety and health constraints, development, system design and operation. So, the safety and health of workers can be seen as a control issue, being managed by a control structure embedded in an adaptive socio-technical system. The purpose of the control structure is to implement restrictions on system development and system operation that ultimately led to safe behaviour. In this context, the occurrence of an accident requires the identification of the causes that determined the control structure to be inefficient. The prevention of future accidents requires a redesign of the control structure. In STAMP, systems are viewed as interdependent components that are maintained in a state of dynamic equilibrium through information feedback and control loops. Such a system is a dynamic process that continuously adapts to achieve its goals and to react to changes in itself and in its environment. This system does not define the management of safety and health at work to prevent events, failures, but is defined as a continuous control task that imposes necessary constraints to limit the behaviour of the system. The basic concepts in STAMP are constraints, control loops and process models and Control levels. Each of these is now described, followed by a classification of accident factors based on new model and basic concepts of systems theory [8].

\section{The role of cognitive functions in the dynamics of work accidents}

\subsection{Cognitive functions}

Cognitive ergonomics is a discipline that deals with the study of mental processes such as perception, memory, reasoning and motor response, which affect interactions among people and other elements of a system, in this case the work system. This discipline provides theoretical and practical information for achieving human-system interaction compatible with human cognitive abilities and limitations, especially in the workplace. Although cognitive functions are essential for safe and efficient operations in the workplace, their importance is not systematically highlighted in economic programs. In this respect, cognitive ergonomics is still an untapped area, although it can make significant contributions to 
improving work performance and creating safe and healthy working environments in industry.

There is research in cognitive ergonomics on relevant topics that include the mental, workload, decision making, performance, human-computer interaction, human reliability, workplace stress and / or training. Therefore, this science mainly studies knowledge and working conditions to optimize human well-being and system performance. In the interaction between a person and the other components of the work system, cognitive ergonomics uses knowledge that comes from the cognitive sciences on mental processes such as perception, attention, memory, decision making and learning. The practical purpose of cognitive ergonomics is to elucidate the nature of human skills and the limitations of information processing, with the specific objective of improving working conditions, human performance, and worker safety and health, avoiding human error, unnecessary workloads and stress. [9, 10].

Cognitive functions are relevant when we talk about 4 essential skills of the worker, namely: sensation and perception, attention, short and long term memory.

\begin{tabular}{|c|c|l|}
\hline $\begin{array}{c}\text { Nr. } \\
\text { crt. }\end{array}$ & Types of skills required & \multicolumn{1}{c|}{ Signification } \\
\hline 1. & Sensation and perception & $\begin{array}{l}\text { signs the perception of stimuli gathered through } \\
\text { the senses, such as sight, hearing, taste, smell and } \\
\text { / or touch. }\end{array}$ \\
\hline 2. & Attention & $\begin{array}{l}\text { stage in which the processing focuses on certain } \\
\text { aspects of the information or processing } \\
\text { perceived can be divided into two or more } \\
\text { aspects. }\end{array}$ \\
\hline 3. & short-term memory & $\begin{array}{l}\text { information storage is available for up to 30 } \\
\text { seconds. }\end{array}$ \\
\hline 4. & $\begin{array}{l}\text { is a permanent stock of different types of } \\
\text { information such as semantic memory that } \\
\text { involves storing knowledge in the world, } \\
\text { symbols and concepts, episodic memory that } \\
\text { covers information about events and episodes, } \\
\text { autobiographical memory that retains events in } \\
\text { an individual's personal life and procedural } \\
\text { knowledge which refers to "knowing how" and } \\
\text { "skills". }\end{array}$ \\
\hline
\end{tabular}

Table 1 - essential skills of cognitive functions

\subsection{Cognitive mechanisms and error classification}

Error, by its very definition, has defining elements that circumscribe the notion itself.

In the work process the notion of human error is related to the existence of some norms, of some rules. Also, the concept of human error is closely related to human actions that cannot be judged psychologically simply as correct actions and erroneous actions. In order to understand the mechanisms that generate the error, a psychological analysis of the activity is necessary, which can look at the error in a negative aspect, but also in a positive aspect, but which. In work psychology and cognitive ergonomics there are few models that explain the mechanisms of error production, and a brief classification of errors together with cognitive mechanisms is presented in the table below [11]: 


\begin{tabular}{|c|l|l|}
\hline $\begin{array}{c}\text { Nr. } \\
\text { crt. }\end{array}$ & \multicolumn{1}{|c|}{ Types of errors } & \multicolumn{1}{|c|}{ Main cognitive components } \\
\hline 1. & errors determined by knowledge & deficiencies from the mental model \\
\hline 2. & errors of representation of reality & $\begin{array}{l}\text { deficiencies in current information and } \\
\text { working memory }\end{array}$ \\
\hline 3. & processing errors & deficiencies of the cognitive model \\
\hline
\end{tabular}

Table 2 - classification of errors according to cognitive mechanisms

\subsection{Cognitive model and processing errors}

In carrying out the work tasks, the worker processes the information at different levels of abstraction, starting from a level based on automatisms to solving problems based on conceptual knowledge. One of the widely accepted models is Rasmussen's (1983) three-level model of cognitive control, which includes the following levels:

Activity based on automatisms; rule-based activity; Knowledge-based activity. In reality, a person works and can perform actions at several levels at the same time. Reason (1990) proposed a widely accepted classification of processing errors based on Rasmussen's cognitive model, according to which there are three fundamental types of errors (corresponding to the three levels of cognitive control) and several forms of errors within each type and which find their origins in cognitive processes [11].

\subsection{Frequent errors in the mechanism of work accidents}

In this paper we will briefly highlight types of errors that are related to the mechanism of a work accident, namely:

\begin{tabular}{|c|c|c|c|}
\hline $\begin{array}{l}\text { Types of } \\
\text { activities }\end{array}$ & $\begin{array}{l}\text { Fundamental } \\
\text { errors }\end{array}$ & Corresponding errors & \\
\hline \multirow{8}{*}{$\begin{array}{l}\text { activity } \\
\text { based on } \\
\text { automatisms }\end{array}$} & \multirow{8}{*}{$\begin{array}{l}\text { Mistakes and } \\
\text { slips }\end{array}$} & \multirow{5}{*}{ inattention } & "double capture" misses \\
\hline & & & $\begin{array}{l}\text { omissions associated to } \\
\text { interruptions }\end{array}$ \\
\hline & & & low intentionality \\
\hline & & & perceptual confusions \\
\hline & & & interference errors \\
\hline & & \multirow{3}{*}{$\begin{array}{l}\text { attentional control } \\
\text { against time }\end{array}$} & omissions \\
\hline & & & repeat \\
\hline & & & reversals of operations \\
\hline \multirow{9}{*}{$\begin{array}{l}\text { rule-based } \\
\text { activity }\end{array}$} & \multirow{9}{*}{$\begin{array}{l}\text { Proactive } \\
\text { control } \\
\text { mistakes }\end{array}$} & \multirow{7}{*}{$\begin{array}{l}\text { incorrect application of } \\
\text { good rules }\end{array}$} & the first exceptions \\
\hline & & & $\begin{array}{l}\text { signs, countersigns, and non- } \\
\text { signs }\end{array}$ \\
\hline & & & information overload \\
\hline & & & the force of a rule \\
\hline & & & the general rules are stronger \\
\hline & & & Redundancy \\
\hline & & & rigidity \\
\hline & & \multirow{2}{*}{ misapplication of rules } & coding defects \\
\hline & & & actions defects \\
\hline \multirow{2}{*}{$\begin{array}{l}\text { knowledge- } \\
\text { based } \\
\text { activity }\end{array}$} & \multirow{2}{*}{$\begin{array}{l}\text { Retroactive } \\
\text { control errors }\end{array}$} & $\begin{array}{l}\text { selectivity of task } \\
\text { information processing }\end{array}$ & \\
\hline & & workspace limitation & \\
\hline
\end{tabular}




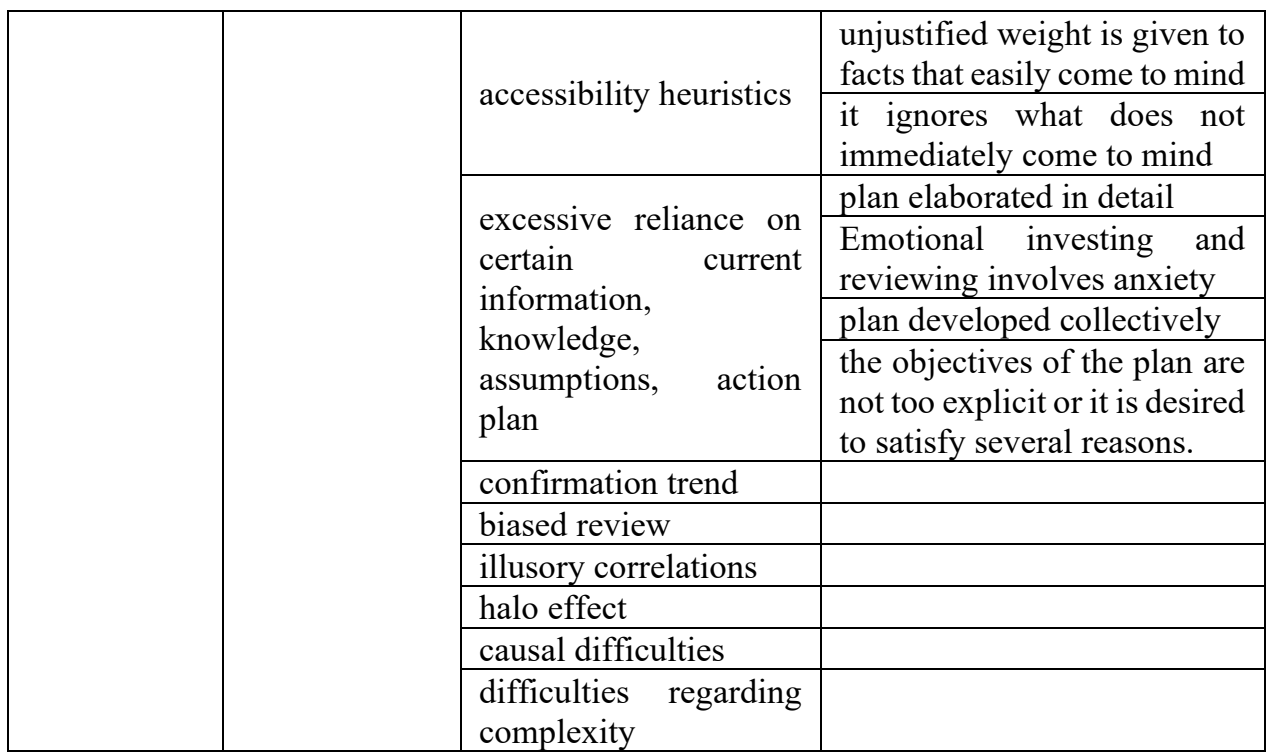

Table 3 - Types of errors related to the mechanism of a work accident.

Regarding this contextual classification, based on studies and research conducted by Reason (1990); Keyser and Woods (1990); Zapf et al. (1992); Kahneman et al., (1982); Miclea (1994) has limitations given that only contextual factors (internal or external to the individual) were taken into account and it is not possible to explain why in identical or similar circumstances, errors do not lead to work accidents [11].

\section{Conclusions}

The results of numerous researches on the nature of human error and the cognitive mechanisms that contribute to their production converge to a unanimously accepted idea that errors are a facet of human activity that cannot be eliminated (Rasmussen, 1987, Reason, 1990, etc.). Also, human error cannot be fully controlled by automated error detection systems, this system being a limited one. People have important abilities to control errors and it is important to understand both the strategies and the mechanisms by which they can manage the errors produced by themselves or others. As can be seen in this paper, we have tried a summary of studies that try to understand the nature of human error and the cognitive mechanisms that contribute to the production of different types of errors.

The growing interest, both scientifically and practically, in the field of error management has created a strong impetus for a new attitude towards human error and the role of the human operator in the control of complex systems. On the other hand, the tendency towards a zeroerror policy - zero work accidents is a problem not only because it ignores the existence of a great variability of human errors but also because some types of errors can be difficult to avoid or control. If we add to these some observations of specialists regarding the "concept of occupational risk assessment" according to which estimating the maximum severity of the consequences of the manifestation can be influenced by the emotional state of people involved in the evaluation process, respectively optimism / pessimism. the worker assumes, estimates and rarely correlates with the values in basic industrial elements we believe that the study of cognitive functions in the dynamics of accidents must be thought in close connection with entrepreneurial management that can influence through subjectivism highlighting dangers or not, can endanger the safety of a priori workers [12]. 


\section{References}

1. M. Greenwood, H.M. Woods, The Incidence of Industrial Accidents upon Individuals with Specific Reference to Multiple Accidents, (Industrial Fatigue Research Board, London, UK, 1919)

2. M. Greenwood, G.A. Yule, J Royal Statist Soc 83,255-271 (1920)

3. D. Michaels, S. Zoloth, Program in Occupational Health, Department of Social Medicine, Montefiore Hospital and Medical Center, Occupational Safety: Do Accidents Happen? (Bronx, New York, 2012)

4. P. Froggatt, J. Smiley, Br J Ind Med January 21, 1-12 (1964)

5. J.C. Burnham, History of Psychiatry 19 (3), 251-274 (2008)

6. H. W. Heinrich, Industrial accident prevention: A scientific approach, (New York, McGrawHill, 1931)

7. P. Underwood, P. Waterson, Advances in Human Aspects of Road and Rail Transportation, (CRC PressEditors, Neville Stanton, 2012)

8. V. Yesilbas, The Relationship Among HFACS Levels and Analysis of Human Factors in Unmanned and Manned Air Vehicles, (Old Dominion University, 2014)

9. N. Leveson, A New Accident Model for Engineering Safer Systems [Online]. Available: http://sunnyday.mit.edu/accidents/safetyscience-single.pdf [Accessed 20 July 2021]

10. I.-J. Kim, Cognitive Ergonomics and Its Role for Industry Safety Enhancements, [Online]. Available: https://www.longdom.org/open-access/cognitive-ergonomics-and-its-role-for-industrysafety-enhancements-2165-7556-1000e158.pdf [Accessed 20 July 2021].

11. G. Iosif, A.-M. Marhan, Ergonomie cognitivă şi interacţiune om-calculator, (Institute of Philosophy and Psychology of the Romanian Academy, Bucureşti, 2005)

12. M.-A. Bernevig, N. M. Lohan, C. Baciu, C. Bejinariu, Acta Universitatis Cibiniensis. Technical Series 66 (1), CC BY-NC-ND 3.0 (2015) 